\title{
Frequency band gap for Rayleigh waves on coated substrates
}

\author{
Nico F. Declercq ${ }^{\text {a) }}$ and Joris Degrieck \\ Soete Laboratory, Department of Mechanical Construction and Production, Ghent University, \\ Sint Pietersnieuwstraat 41, 9000 Gent, Belgium \\ Oswald Leroy \\ Interdisciplinary Research Center, Katholieke Universiteit Leuven Campus Kortrijk, E. Sabbelaan 53, \\ 8500 Kortrijk, Belgium
}

(Received 3 February 2004; accepted 7 May 2004)

The Rayleigh wave velocity for a coated substrate must have a value in between the ones for the substrate material and the coating material. Nevertheless, Adler and McCathern [J. Appl. Phys. 49, 2576 (1978)] have performed measurements, based on the Schoch effect, on a stainless steel substrate covered with an aluminum oxide coating that contradict this phenomenon. The current letter describes the frequency band gap effect for Rayleigh waves on coated substrates and explains how this phenomenon is related to the cited measurements. The existence of such a gap can be very important for the development of frequency filters. (C) 2004 American Institute of Physics. [DOI: $10.1063 / 1.1766406]$

Coatings are very common in materials technology. ${ }^{1}$ Rayleigh waves are often used in nondestructive testing and in electronic devices. They are also important in seismology. In the past they have frequently been used as a means to characterize coatings on substrates. ${ }^{2-4}$ When bounded beams are incident from water onto a coated surface at the "substrate Rayleigh angle," the Schoch phenomenon appears and its characteristics are determined by the properties of the coating. ${ }^{2-4}$ Because a Rayleigh wave on a coated substrate is influenced by both the coating and the substrate, it is clear that the characteristics of this Rayleigh wave must be situated in between the ones of such waves on homogeneous solids consisting of pure substrate material or consisting of pure coating material. Therefore one expects a Rayleigh wave velocity bounded by the Rayleigh wave velocities on the pure solids. It is believed that the Rayleigh wave velocity can be found by measuring the angle at which the Schoch effect occurs when a bounded sound beam is reflected from a solid in water. ${ }^{2-7}$ Adler and $\mathrm{McCathern}{ }^{5}$ found a combination of coating $\left(\mathrm{Al}_{2} \mathrm{O}_{3}\right)$ and substrate (stainless steel) for which the Schoch effect corresponds with a Rayleigh wave velocity that is lower than the one on any of the composed materials. This is so surprising that an explanation has never been found. In what follows it will be seen that if the properties of the coating and the substrate differ too much (e.g., $\mathrm{Al}_{2} \mathrm{O}_{3}$ on stainless steel), there exists a frequency gap in which Rayleigh waves cannot exist in the composite system. ${ }^{7}$ The cited experiments correspond to such a gap and therefore what causes the Schoch phenomenon in Ref. 5 cannot be a Rayleigh wave.

The interaction of sound with the system of isotropic layers has been simulated by a linear combination of all possible plane wave solutions in the coating, i.e., for each type of wave (shear and longitudinal) we have one upward propagating shear wave and one downward propagating shear wave. For the incidence media (water) there is only one incident wave and one reflected wave, for the substrate there is

\footnotetext{
${ }^{\text {a) }}$ Author to whom correspondence should be addressed; electronic mail:
} nicof.declercq@ugent.be one shear and one longitudinal transmitted wave. The wave vectors of each of the waves are determined by the law of Snell-Descartes ${ }^{8-12}$ and by the dispersion relation for plane waves. ${ }^{8-11}$ The amplitude attributed to each wave is found by considering continuity of the normal stress vector and normal displacement on the water-solid interface and continuity of the normal stress vector and total displacement on the solid-solid interface. ${ }^{13}$ In our calculations and in the figures that are given in the following, the Cartesian axes $x$ and $y$ are used with $z$ pointing from the incidence media to solid media, whereas $x$ is parallel to the interface. The $z=0$ position corresponds to the coating-substrate interface.

The physical properties of the considered materials are given in Table I. Just as in Ref. 5 we have considered a coating thickness of $0.24 \mathrm{~mm}$. In Fig. 1 the reflected "homogeneous plane wave" amplitude and phase are plotted as a function of the angle of incidence for $1 \mathrm{MHz}$. It is noticed that, for a given configuration, a phase shift of $\pi$ occurs at the Rayleigh angle. This angle is $30.33^{\circ}$ for a stainless steel half space, $15.52^{\circ}$ for a $\mathrm{Al}_{2} \mathrm{O}_{3}$ half space, $28.15^{\circ}$ for a $\mathrm{Al}_{2} \mathrm{O}_{3}$ coating on stainless steel substrate, and $17.18^{\circ}$ for a stainless steel coating on a $\mathrm{Al}_{2} \mathrm{O}_{3}$ substrate. Hence nothing extraordinary happens because the Rayleigh angles (and hence their velocities) for the coated substrates are situated in between the ones for the uncoated substrates. However, in Fig. 2 the reflected amplitude and phase are plotted for a $\mathrm{Al}_{2} \mathrm{O}_{3}$ coated stainless steel substrate not only as a function of the angle of incidence, but also as a function of the frequency. It is noticed that in between 1.57 and $23.23 \mathrm{MHz}$ no phase shift of $\pi$ occurs. Therefore Rayleigh waves are not stimulated in

TABLE I. Physical properties of used materials.

\begin{tabular}{lccc}
\hline \hline & $\begin{array}{c}\text { Density } \\
\left(\mathrm{kg} / \mathrm{m}^{3}\right)\end{array}$ & $\begin{array}{c}\text { Longitudinal wave } \\
\text { velocity }(\mathrm{m} / \mathrm{s})\end{array}$ & $\begin{array}{c}\text { Shear wave } \\
\text { velocity } \\
(\mathrm{m} / \mathrm{s})\end{array}$ \\
\hline Water & 1000 & 1480 & $\ldots$ \\
Stainless steel & 8090 & 5610 & 3180 \\
$\mathrm{Al}_{2} \mathrm{O}_{3}$ & 4000 & 10460 & 6010 \\
Brass & 8100 & 4840 & 2270 \\
\hline \hline
\end{tabular}



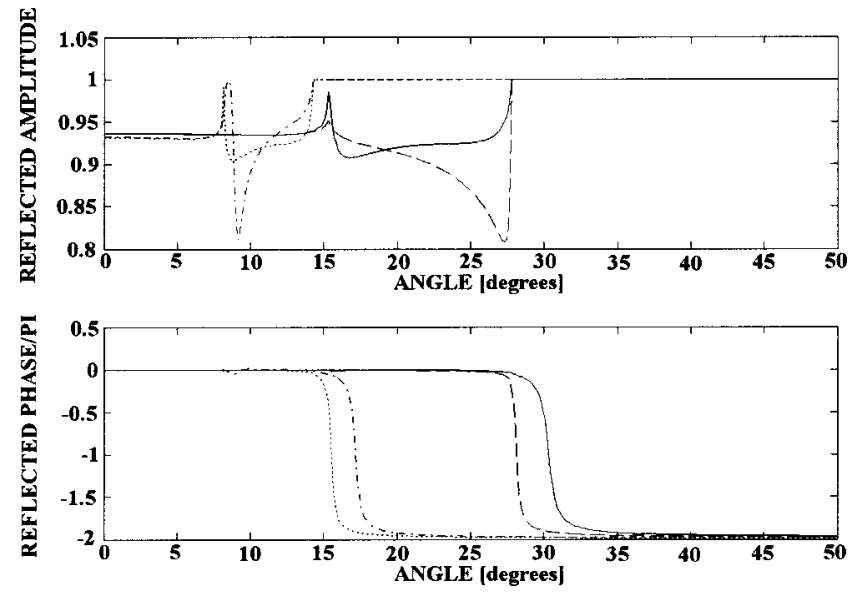

FIG. 1. Reflected amplitude (top) and reflected phase (bottom), at $1 \mathrm{MHz}$, as a function of the angle of incidence, for a stainless steel (solid line), $\mathrm{Al}_{2} \mathrm{O}_{3}$ (dotted line), $0.24 \mathrm{~mm} \mathrm{Al} \mathrm{O}_{3}$ coating on stainless steel (dashed line), $0.24 \mathrm{~mm}$ stainless steel coating on $\mathrm{Al}_{2} \mathrm{O}_{3}$ (dash-dot line).

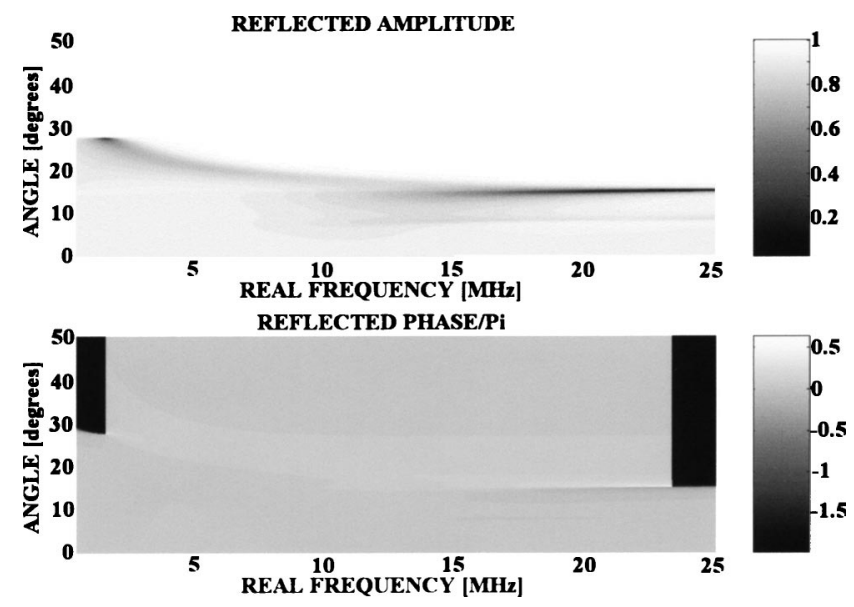

FIG. 2. Reflected amplitude (top) and reflected phase (bottom) for $0.24 \mathrm{~mm}$ $\mathrm{Al}_{2} \mathrm{O}_{3}$ coating on stainless steel as a function of the angle of incidence and on the frequency. It is seen that there is a gap between 1.57 and $23.23 \mathrm{MHz}$ where Rayleigh waves cannot exist.

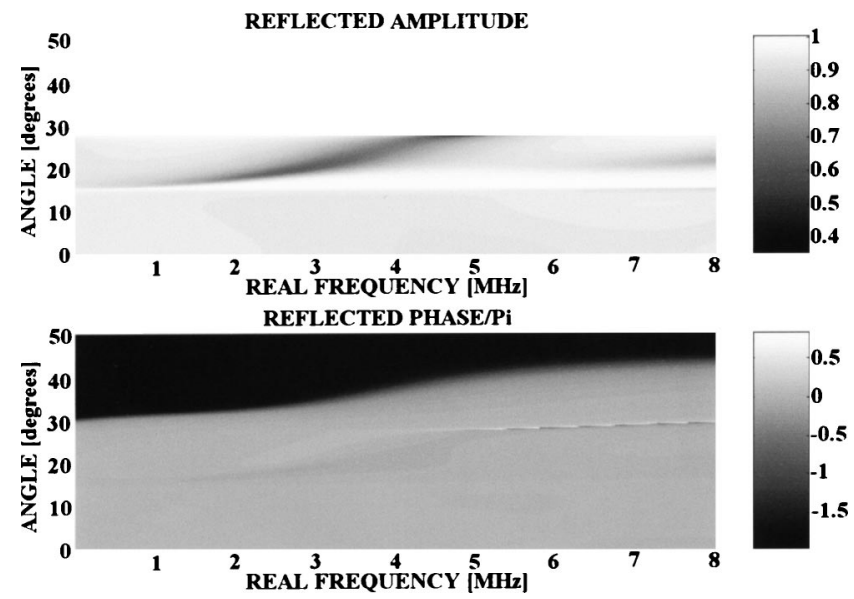

FIG. 3. Reflected amplitude (top) and reflected phase (bottom) for $0.24 \mathrm{~mm}$ brass coating on stainless steel as a function of the angle of incidence and on the frequency. There is no frequency gap visible.

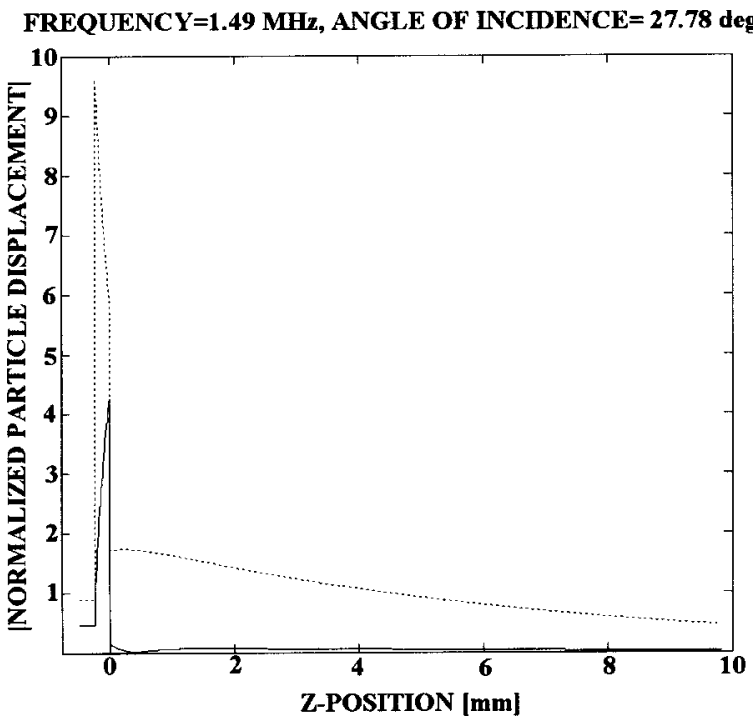

FIG. 4. Particle displacement $(u)$ profile at $1.49 \mathrm{MHz}$ and incidence angle $27.78^{\circ}$. Solid line: $\left|u_{x}\right|$, dotted line $\left|u_{z}\right|$. Although disturbed by the coating $(0<x<-0.24 \mathrm{~mm})$, a typical Rayleigh wave pattern is visible in the substrate $(x>0)$. The amplitude is also fairly high.

that region. This "forbidden" region is therefore a frequency "gap." The gap exists because the physical properties of stainless steel and $\mathrm{Al}_{2} \mathrm{O}_{3}$ differ too much. For certain frequencies the coating does not just disturb the Rayleigh wave on the substrate, but simply destroys it. In Fig. 3 it can be seen, by means of the example of a brass coating on stainless steel, that no gap appears if the coating and substrate are more alike. Figure 4 shows the particle displacement pattern, for the $\mathrm{Al}_{2} \mathrm{O}_{3}$ coating on stainless steel, at the Rayleigh angle outside the gap (the Rayleigh wave pattern is visible), whereas Fig. 5 shows the pattern inside the gap, exactly at the angle where in Ref. 5 the Schoch effect was observed. It is seen that there is no Rayleigh wave pattern present in Fig. 5. It is also interesting to remark in Figs. 2 and 3 that the

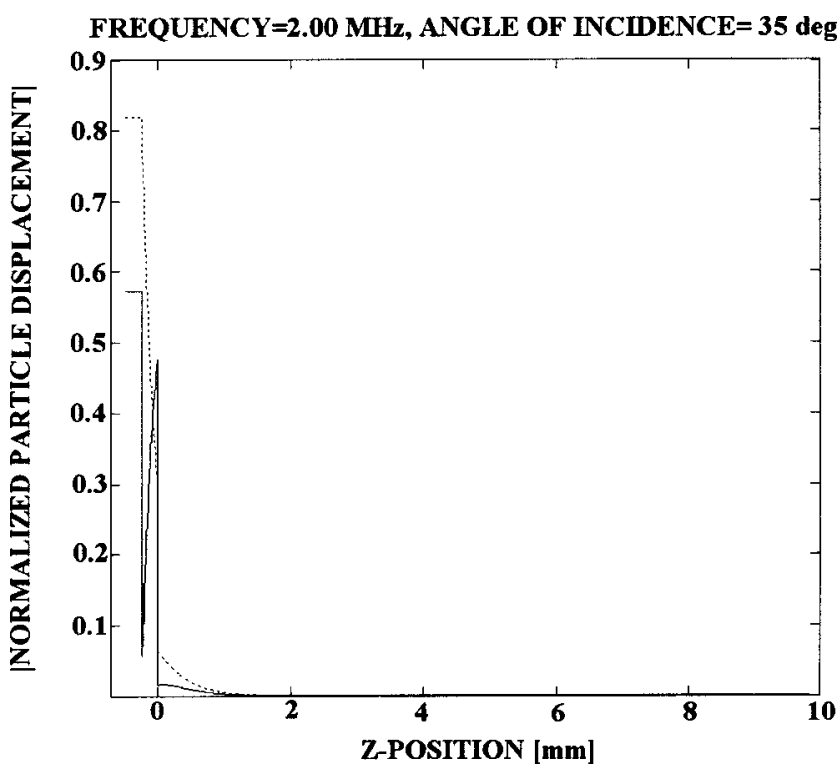

FIG. 5. Particle displacement $(u)$ profile at $2 \mathrm{MHz}$ and incidence angle $35^{\circ}$. Solid line: $\left|u_{x}\right|$, dotted line $\left|u_{z}\right|$. This corresponds to the situation of Ref. 5. Because the frequency is part of the gap, no Rayleigh wave pattern is visible. Also the amplitude in the substrate is very small if compared with Fig. 4. 
presence of a coating makes Rayleigh waves dispersive, i.e., their velocity depends on the frequency. ${ }^{14}$

It has been shown that if the physical properties of the coating and the substrate differ too much, that there exists a frequency gap in which no Rayleigh waves can exist. ${ }^{15}$ The gap extent is function of the coating thickness and the coating material. The experiments in Ref. 5 have been performed in that gap region. Therefore whatever is the cause of the Schoch effect in the experiment, it cannot be attributed to a Rayleigh wave. Part of the investigation which is not described in this letter was done by application of the Fourier $\operatorname{method}^{15}$ as well as the inhomogeneous wave method ${ }^{16-19}$ to describe bounded beams and to find the Schoch phenomenon for all angles of incidence in the experimental configuration of Ref. 5 and it has not been found. Therefore both theories are unable to describe what causes the Schoch effect in Ref. 5 , whence new models must be developed to discover the physical cause of the effect. Nevertheless the study reveals the presence of a frequency gap, which is extremely interesting for the development of frequency filters.

This work was supported by "The Flemish Institute for the Encouragement of the Scientific and Technological Research in Industry (I.W.T.)."
${ }^{1}$ E. Dekempeneer, K. Van Acker, J. Meneve, D. Neerinck, S. Eufinger, and W. Pappaert, Surf. Coat. Technol. 142, 669 (2001).

${ }^{2}$ S. Devolder, O. Leroy, M. Wevers, and P. De Meester, Acust. Acta Acust. 82, 372 (1996).

${ }^{3}$ F. W. Windels, S. Vanaverbeke, and O. Leroy, J. Acoust. Soc. Am. 110, 1349 (2001)

${ }^{4}$ S. Vanaverbeke, F. Windels, and O. Leroy, Acust. Acta Acust. 89, 640 (2003).

${ }^{5}$ L. Adler and D. A. McCathern, J. Appl. Phys. 49, 2576 (1978).

${ }^{6}$ A. Schoch, Acustica 2, 1 (1952).

${ }^{7}$ A. Schoch, Acustica 2, 18 (1952).

${ }^{8}$ R. Briers, O. Leroy, O. Poncelet, and M. Deschamps, J. Acoust. Soc. Am. 106, 682 (1999).

${ }^{9}$ M. Deschamps, B. Poiree, and O. Poncelet, Wave Motion 25, 51 (1997).

${ }^{10}$ W. Huang, R. Briers, S. I. Rokhlin, and O. Leroy, J. Acoust. Soc. Am. 96, 363 (1994).

${ }^{11}$ J. Roux, in Physical Acoustics: Fundamentals and Applications, edited by O. Leroy and M. Breazeale (Plenum, New York, 1991), pp. 155-164.

${ }^{12}$ N. F. Declercq, J. Degrieck, and O. Leroy, Appl. Phys. Lett. (in press).

${ }^{13}$ A. H. Naefeh, Wave Propagaton in Layered Anisotropic Media with Applications to Composites (North-Holland, Amsterdam, 1995).

${ }^{14}$ D. E. Bray, D. M. Egle, and L. Reiter, J. Acoust. Soc. Am. 64, 845 (1978).

${ }^{15}$ N. F. Declercq, R. Briers, and O. Leroy, Ultrasonics 40/1-8, 345 (2002).

${ }^{16}$ N. F. Declercq, J. Degrieck, R. Briers, and O. Leroy, J. Acoust. Soc. Am. 112, 2414 (2002)

${ }^{17}$ N. F. Declercq, J. Degrieck, R. Briers, and O. Leroy, Appl. Phys. Lett. 82, 2533 (2003).

${ }^{18}$ N. F. Declercq, J. Degrieck, and O. Leroy, Ultrasonics 42, 273 (2004).

${ }^{19}$ N. F. Declercq, J. Degrieck, and O. Leroy, Acust. Acta Acust. 89, 1038 (2003). 
Applied Physics Letters is copyrighted by the American Institute of Physics (AIP). Redistribution of journal material is subject to the AIP online journal license and/or AIP copyright. For more information, see http:/ojps.aip.org/aplo/aplcr.jsp

Copyright of Applied Physics Letters is the property of American Institute of Physics and its content may not be copied or emailed to multiple sites or posted to a listserv without the copyright holder's express written permission. However, users may print, download, or email articles for individual use. 